\title{
A UTOPIA DO DIREITO À CIDADE: POSSIBILIDADES DE SUPERAÇÃO DA DICOTOMIA FAVELA-BAIRRO NO RIO DE JANEIRO ${ }^{1}$
}

\author{
MÁRCIO PIÑon DE OliveIRA ${ }^{2}$ \\ Universidade Federal Fluminense
}

\section{Introdução}

\begin{abstract}
Aos amigos Eliezer, Zé Antônio, Nilton, Reinaldo, e Pingo, lembranças de uma infância democrática e feliz com a favela.
\end{abstract}

Não faz muito tempo podíamos entrar na favela sem medo de sermos abordados por policiais ou "soldados" do comando local ligado ao narcotráfico. Trago, em minha memória, boas imagens e registros da convivência que tinha com amigos de escola e de rua, que eram moradores de favelas, no Bairro da Penha, subúrbio da cidade do Rio de Janeiro, ramal da Estrada de Ferro da Leopoldina ${ }^{3}$. Nos idos dos anos sessenta, estudávamos juntos numa escola municipal, próximo ao Largo da Penha, onde se iniciava a ladeira que nos levava ao pé da escadaria da Igreja da Penha, um dos pontos turísticos de nossa cidade.

$\mathrm{Na}$ favela da Vila Cruzeiro tinha três grandes amigos: Eliezer, Zé Antonio e Nilton. Estudávamos na mesma turma da escola pública (EP São Vicente). Convivi com eles da terceira à sexta série do antigo primário, quando então fazíamos o concorrido

\footnotetext{
${ }^{1}$ Trabalho apresentado no IX Simpósio Nacional de Geografia Urbana-Manaus/AM, 18 a 21 de outubro de 2005 - como parte da Comunicação Coordenada "Espaços de (re)produção da vida na metrópole: sociabilidade e utopia".

2 Professor Adjunto do Departamento de Geografia e do Programa de Pós-Graduação em Geografia da UFF; marpinon@vm.uff.br.

${ }^{3}$ Foi exatamente numa das favelas desta localidade, a Vila Cruzeiro, que ocorreu, em junho de 2002, 0 seqüestro e o assassinato do jornalista Tim Lopes, quando fazia reportagem sobre os bailes funks na região.
} 
exame de admissão para o Ginasial. Freqüentávamos a casa uns dos outros. Assim, com uma certa regularidade lá estava eu na favela para brincar ou para fazermos algum trabalho da escola. Íamos mais à casa de Eliezer e Zé Antonio que moravam na parte mais baixa, uma vez que a casa de Nilton já ficava na parte alta do morro. Lá passei boas tardes da minha infầncia em "torneios de jogo botão" e desafios de "bafobafo" (jogo de virar figurinhas). Também nos reuníamos para os famosos trabalhos de grupo da escola, de temas variados, normalmente de motivos cívicos, comuns em tempo de ditadura militar, e onde conversávamos mais do que pesquisávamos e colávamos figuras em cartolinas.

Eliezer era filho de migrantes nordestinos, pernambucanos, salvo engano. Sua tez era branca, olhos azuis e cabelo louro, as vezes era chamado de alemão, russo ou "filho do padeiro", como costumávamos brincar. Seu pai trabalhava na construção civil e sua mãe estava sempre em casa. Tinha ainda duas irmãs, que nunca víamos, pois eram mais velhas e já trabalhavam para ajudar na renda da família. A coisa de que mais gostávamos de sua casa era o bolo de milho que sua mãe servia com refresco ou café com leite, quando tinha. Em sua casa havia água e luz, mas o banheiro ficava ainda do lado de fora, num cômodo separado. Já Zé Antonio era filho único de um casal de portugueses e era quase vizinho de Eliezer. Seu pai era porteiro de um prédio no centro da cidade e sua mãe não trabalhava. Ele estava sempre com a roupa arrumadinha e engomada. $\mathrm{O}$ mais gostoso de sua casa era o pão quente que sua mãe servia com café (acho que foi aí que, pela primeira vez, bebi café puro em minha vida e gostei). Nilton, ou "funga-funga", como o chamávamos, pois vivia com uma coriza permanente, era de tez negra e o que possuía mais dificuldades nos estudos de todos nós. Tinha muitos irmãos, sete, me recordo, e sua mãe os criava sozinha, pois o seu pai a havia deixado. Ela nunca estava em casa, pois trabalhava fora como doméstica, e Nilton era quem ajudava a tomar conta dos irmãos menores e a pegar água todo o dia de manhã, antes de ir para a escola, pois sua casa não possuía água encanada nem energia elétrica. Quando havia reunião de pais na escola era sempre a sua irmã mais velha que ia no lugar da mãe e a professora reclamava que o Nilton sempre dormia durante as aulas. $\mathrm{O}$ que mais gostávamos de fazer em sua casa era soltar pipa, pois por ser mais alto o lugar tínhamos vantagem nos "cruzas".

Eles também gostavam muito de freqüentar a minha casa. Na época, morávamos num apartamento alugado, num prédio que era um dos poucos do lugar, num loteamento chamado "Bairro Dourado", dominado por casas, que ficava atrás da antiga oficina de bondes da cidade, que depois se transformou em garagem da CTC (Companhia de Transportes Coletivos) e ao lado do "arraial da Penha", onde se encontra, até os dias atuais, o conhecido e tradicional parque de diversões Shangai. Meu pai era comerciário e trabalhava em uma loja no centro da cidade, na Rua da Alfândega e aos domingos como barraqueiro na feira de Caxias para aumentar a renda da família. Minha mãe era "do lar", como se dizia, mas na época já se iniciava na arte de fazer bolos e doces para fora. Lá em casa o que mais gostávamos de fazer, quando não éramos atrapalhados 
por minha irmã, três anos mais nova, era jogar bola ou brincar de pique nos pilotis do prédio ou mesmo na rua, onde tínhamos mais espaço, uma vez que na favela as casas eram mais juntas e as ruas mais estreitas, excetuando-se a área do campo de futebol no Parque Proletário da Vila do Cruzeiro que ninguém invadia com casas.

Havia ainda o Reinaldo, um outro amigo de turma da escola, que morava um pouco mais distante, na subida do Morro do Grotão, no final da Rua Aymoré. Ele era o único filho de uma família que tinha uma situação econômica melhor que os demais. Era de tez branca, seu pai era motorista de táxi, proprietário do próprio veículo. Com ele fomos por mais de uma vez ao Maracanã, de carona com o seu pai taxista.

Pingo era o apelido de um outro amigo, cujo nome eu nunca soube de fato. Este era um amigo de brincadeiras de rua que morava no Morro da Penha (ao lado da Igreja da Penha ${ }^{4}$ ), o mais próximo da minha casa. Morava no topo do morro, num barraco de madeira, sem água e sem luz. Nunca cheguei a conhecer a sua casa, pois que eu me lembre, ele nunca me convidou também para ir lá. Sabia que era filho temporão e sua mãe tinha mais idade, era viúva e adoentada, não podendo trabalhar fora. Seus irmãos já tinham todos mais idade e não moravam com ele. Ele não estudava, e sustentava a casa com o seu trabalho, vendendo amendoim torrado todos os dias no final da tarde, na Estação da Penha e nos trens da linha da Leopoldina. Muitas vezes, antes de ir trabalhar, parava para jogar conosco na rua a pelada de fim de tarde, enquanto o amendoim torrava na lata encostada no canto da calçada. Era o maior filão de "bóia" da rua, não precisava ninguém oferecer que ele já ia pedindo. Um dia o Pingo desapareceu e nunca mais tivemos notícias dele.

\section{O Espaço Público como Mediação}

\section{"Escuta-se a cidade como se fosse uma música tanto quanto se a lê como se fosse um texto."}

(Henry Lefebvre - $\mathrm{O}$ direito à cidade)

Esse imaginário de infância é muito significativo em minha trajetória de vida e hoje, podendo revê-lo através do estudo e da pesquisa da cidade, podemos aferi-lo também quanto ao rumo que o processo de urbanização tomou no mundo e em escala nacional, com projeções na cidade do Rio de Janeiro. É evidente que este processo foi e é bem mais complexo que as experiências de vida transcritas em alguns poucos registros de uma memória de infância, há cerca de quarenta anos atrás. Mas é fato também que traz elementos e contornos bastante importantes na recuperação de um tempo e espaço reais, nos quais eram possíveis relações interpessoais onde as diferenças sociais e culturais existentes se faziam presentes e conviviam no tecido urbano, não se

\footnotetext{
${ }^{4}$ Atualmente ao se entrar e sair da cidade, via Aeroporto Internacional ou Linha Vermelha, é possível avistar a Igreja da Penha no alto do penhasco no bairro a que ela deu nome.
} 
encontrando completamente apartadas.

É importante notar também o papel que a escola pública e a rua tinham como mediações para uma convivência mais democrática e plural, como espaços do vivido. Através da escola e da rua nos era possível viver espaços de relações que nos permitiam a socialização de experiências da vida cotidiana diferenciadas de acordo com o habitat de cada um, fosse ele a favela ou o bairro já urbanizado. Não havia, a princípio, interdições para que a troca se estabelecesse entre indivíduos de origens sociais e culturais distintas. Na escola ou na rua, os diferentes, embora não se igualassem, nem mudassem a sua condição socioeconômica e cultural, socializavamse via a educação e a ludicidade. E isto assegurava, através das crianças, momentos e lugares de interação entre aqueles que moravam na favela e os que moravam no bairro. É certo que a distinção social e espacial se fazia presente entre e intra cada um dos lugares, mas o ir e vir, mesmo que de forma etariamente seletiva, encontrava-se presente.

No caso da escola pública, em particular, este papel ia para além do convívio em seu espaço físico, pois ao permitir e tecer relações de amizade entre os diferentes indivíduos extravasava para fora dos seus limites esta interação/socialização. Muitas vezes esta socialização acabava por envolver irmãos e irmãs dos amigos, seus amigos e se estendendo para além em relações de amizade entre os adultos, pais daqueles que estabeleciam encontros diários na escola, e em outros espaços: o da feira-livre, onde se encontravam em geral as mulheres (mães) e o do futebol, mais reservado aos homens - pais, tios e primos. Outro espaço, ainda, de interação era o dos blocos carnavalescos, em geral localizados em ruas de acesso ou bem próximas às favelas. Neles encontrávamos tanto pessoas das comunidades de favela quanto moradores do asfalto, como era comum se referir a estes.

É notório o papel que o samba e as escolas de samba tiveram também nesta socialização e interação entre espaços populares e o conjunto da cidade dita formal no Rio de Janeiro, sobretudo nos subúrbios e bairros da zona norte (FERNANDES, 2001).

Neste pequeno percurso feito até aqui podemos assinalar três pontos importantes no que toca e compõe o direito à cidade: o direito de ir e vir e circular livremente nos diferentes espaços da cidade; o direito ao espaço público, ao seu uso e apropriação; e o direito aos serviços e aos equipamentos públicos.

\section{Do Direito à Cidade no Rio de Janeiro}

Falar em direito à cidade remete-nos para pensar o que está reservado às novas gerações. Os jovens que crescem "olhando a cidade" do alto dos morros também fazem parte dela, ajudam a construí-la material e simbolicamente. Sonham com a felicidade. Estudam, trabalham, casam-se ou não, criam filhos, compõem músicas, dançam, inventam linguagens e tradições, aprendem e ensinam muitas coisas, relacionam-se com "a cidade" de diversas formas, mas de fato, são poucos os que se sentem verdadeiramente como parte dela. Estão sempre precisando sair para 
"conquistá-la", para desafia-la ou simplesmente para nela se afirmar como pessoa.

A utopia do direito à cidade, no caso específico do Rio de Janeiro, começa, obrigatoriamente, pela superação da visão dicotômica favela-cidade. Para isso, é preciso que os moradores da favela possam sentir-se tão cidadãos quanto os que têm moradias fora das favelas.

Por outro lado, o direito à cidade, como possibilidade histórica, não pode ser pensado exclusivamente a partir da favela. Mas as populações que aí habitam guardam uma contribuição inestimável para a construção prática desse direito. Isso porque, das experiências vividas, emergem aprendizados e frutificam esperanças e soluções. Em meio às dores e perdas, ainda nascem conquistas.

É certo que, paradoxalmente, já houve tempos melhores ou com outras distinções sociais e territoriais. Um passeio pelas memórias de moradores do Rio de Janeiro dos anos 1960 e 1970, como descrevemos anteriormente, ainda apresenta imagens e registros da convivência entre amigos de escola e de rua, que brincam e aprendem juntos, jovens e crianças moradoras das favelas e dos bairros que as circundam. Também já existiu um movimento associativo e reivindicatório de bairros e favelas mais forte, maior liberdade para transitar-se dentro da favela, mais aglutinação cultural espontânea, sem a mediação do mercado e/ou de projetos sociais direcionados para elas pelo poder público e diferentes organizações não-governamentais.

Os moradores mais jovens das favelas cariocas de hoje não fazem idéia desse tempo, não partilham essa memória. Os mais velhos na sua grande maioria, não entendem como as mudanças se operaram, inconformados com a violência ou reféns dela - agora não só simbólica, mas física - que passou a comandar as relações. Pensar o direito à cidade como utopia coloca o desafio de ter esse quadro como referência, mas ir para além dele. Não foram as mudanças que se operaram na favela que distanciaram, ainda mais, o horizonte de conquistas que poderiam apontar para outra alternativa histórica. A favela foi envolvida, como parte das mutações que atravessaram a cidade como um todo. Porque a favela é a cidade e a cidade é a favela.

Então, cabe perguntar: a utopia do direito à cidade esgota-se na idéia de que a favela alcance benefícios que parecem privilégio daquela "cidade" que a ela se opõe? Será que a cidade situada na utopia de direito constituída a partir da favela pode ser essa que a favela conhece? A utopia do direito à cidade tem de levar à favela a própria utopia da cidade. Uma cidade que não se fragmente em oposições asfaltofavela, norte-sul, praia-subúrbio e onde todos tenham direito ao(s) seu(s) centro(s). Oposições que expressam muito mais do que diferenças de localização e que se apresentam recheadas de segregação, estereótipos e ideologias.

Para que a favela seja pólo de um desejo que impulsione a busca do direito à cidade, é necessário que ela se pense como parte da história da própria cidade. É necessário que seja compreendido de onde vem a idéia de utopia ligada a um conceito de cidade. Tudo isso ultrapassa a favela, transborda a cidade do Rio de Janeiro no tempo e no espaço. 


\title{
A utopia do Direito à Cidade
}

\author{
A gente não quer só comida, \\ A gente quer comida, diversão e arte. \\ A gente não quer só comida, \\ A gente quer saída para qualquer parte. \\ (Titãs - Autores: Arnaldo Antunes / \\ Marcelo Fromer + Sergio Britto)
}

Nos versos acima, os autores dessa conhecida canção, expressam as suas demandas no mundo prático-sensível do cotidiano: "a gente não quer só comida", ou seja, a gente não quer só a subsistência, a reprodução da vida apenas. Isso nos iguala ainda à condição de animal. Dela devem fazer parte como necessidades à diversão e a arte. Como a gente também "quer saída para qualquer parte", isto é, saídas físicas, literalmente, com liberdade de ir e vir, e saídas existenciais, culturais e políticas, com direito de livre associação, expressão de idéias, projetos ou criações.

Historicamente, o lugar geográfico para o qual convergiram essas demandas ou aspirações do homem - do ter, do ser e do querer - foram as cidades. Nesse sentido, a cidade, como expressão material e simbólica da sociedade, já nasce como aquele lugar para o qual se projetava um ideal de civilização e de felicidade, ou seja, o de concretização de uma utopia.

$\mathrm{Na}$ antiga Grécia, primeiro grande momento da cidade, esta surge como um encontro político entre homens e o seu território, a polis, embasada num ideal civilizatório. Para Aristóteles a finalidade última da polis era promover a felicidade dos cidadãos e estes, embora desempenhassem funções dessemelhantes, deveriam todos trabalhar para a conservação de sua comunidade. "Mas não é apenas para viver juntos, mas sim para bem viver juntos que se fez o Estado".

Contudo, na polis grega nem todos tinham "direito à cidade", isto é, nem todos podiam circular livremente pelos diferentes espaços da cidade, nem todos tinham acesso ao espaço público e ao seu uso, como nem todos podiam exercer funções públicas. A cidadania era seletiva e restrita e dela encontravam-se excluídas as crianças, as mulheres e os escravos.

Mais do que um dado externo, um conjunto de formas, habitações, monumentos, templos e instituições, a cidade seria também o resultado da divisão do trabalho e suas modalidades múltiplas, que nela encontravam lugar. "À cidade incumbe o trabalho intelectual: funções de organização e de direção, atividades políticas e militares, elaboração do conhecimento teórico (filosofia e ciências)" (LEFEBVRE, 1991: 28-

\footnotetext{
${ }^{5}$ Por Estado lê-se aqui também a polis, expressão política e geográfica ao mesmo tempo da cidade. Cf. ARISTÓTELES, 1991. p.41.
} 
29), bem como os mais diferentes tipos de arte ou poiésis. Assim a cidade é duplamente ato e obra, fruto do trabalho humano e criação.

Na sociedade moderna, o primeiro sentido do direito à cidade é o da cidade como o lugar do direito (ANSAY E SCHOONBRODT, 1989:40).

A cidade como lugar de direito remete à constituição de um direito individual garantido ao servo que se libertava da sujeição ao senhor, na sociedade medieval. No território urbano (burgo) e através de suas instituições, proclamava-se um novo direito, como o de ir e vir e o da livre associação e iniciativa, que sintetizava novas regras de vida em comum.

Inaugurar-se-ia uma sociedade fundada sobre a associação livre de produtores. Novos atores e novos papeis ganhariam relevo. Aqueles homens criaram uma nova concepção e uma nova prática de legitimidade política baseada na associação de interesses econômicos da burguesia. A cidade tornou-se, pouco a pouco, autônoma, possuindo seus próprios direito e governo, justiça, finanças e defesa, organizados por ela mesma. Entretanto, nela, o cidadão é concebido em termos estritamente individuais (OLIVEIRA, 1999:99).

É importante lembrar que "a luta prática dos atores urbanos precedeu a reflexão teórica e circunscreveu a imbricação das lutas em torno de um conceito polissêmico: $o$ direito à cidade" (ANSAY e SCHOONBRODT, 1989:38). No primeiro momento, esta luta foi por aqueles direitos conhecidos como naturais - os direitos civis e os direitos políticos - que foram consagrados, mais tarde, pelas revoluções burguesas.

Nessa perspectiva, "o direito à cidade se manifesta como forma superior dos direitos: direito a liberdade, à individualização na socialização, ao habitat e ao habitar", bem como "o direito à obra (à atividade participante) e o direito à apropriação (bem distinto do direito à propriedade)" (LEFEBVRE, 1991:135). Em outras palavras, significa a pretensão que pode manifestar cada indivíduo de habitar a cidade porque ela é o espaço jurídico novo, de realização de suas aspirações como homem, fonte concreta de emancipação. Assim, a cidade é a estrutura espacial e social em que historicamente se consubstancia a idéia de direitos do homem, visto que a vida urbana insere o indivíduo numa "rede de práticas contratuais e relações formais". Ter direito à cidade significa, portanto, a reivindicação do "direito" ao direito, o acesso e a participação a uma sociedade contratual e a tudo que ela possa possibilitar na vida urbana. (ANSAY E SCHOONBRODT, 1989:40). O direito à cidade aparece aqui como condição para a realização dos demais direitos.

$\mathrm{O}$ segundo sentido do direito à cidade, que viria com o surgimento e o desenvolvimento do Estado Moderno, seria o da reivindicação, pelo indivíduo, de recursos institucionais necessários ao seu bem-estar (1989:40).

Aqui a cidade aparece como "organização espacial concreta da providência social e da riqueza", seja pelo mundo ou pelas "mediações complexas que constituem seus espaços, suas instituições, seu bom funcionamento" (1989:40).

No seu dia-a-dia os homens se encontram na cidade para o trabalho, para as compras, 
para a diversão e para as tarefas de reprodução do corpo e da vida. Para tanto, precisam habitar com dignidade, movimentar-se e desempenhar ações necessárias para o bom funcionamento da sociedade urbana e para o seu bem-estar. Até mesmo quando dormimos ou repousamos, é necessário que um grupo de homens esteja trabalhando e cuidando para que possamos fazê-lo com tranqüilidade e segurança. Neste sentido, a cidade, além de precisar proporcionar ao citadino o seu morar e o seu trabalho, necessita ter todos os meios para que a vida social nela se reproduza a contento.

O conjunto de edifícios públicos que abrigam a burocracia do governo, os equipamentos sociais coletivos (escolas, hospitais, postos de saúde, etc), o espaço público e suas redes (jardins, praças, ruas, vias expressas, etc), seu patrimônio cultural (estádios, teatros, cinemas, etc) e todo o mobiliário urbano, que compõe o ambiente social construído, fazem parte dos dispositivos territoriais necessários ao bom funcionamento da cidade e aos quais também devemos ter direito.

No dizer de Lefebvre, "na sociedade moderna, o Estado subordina a si os seus elementos e materiais, entre os quais a cidade. Todavia, esta continua a ser uma espécie de subsistema no sistema total, filosófico-político, com o sistema das necessidades, o dos direitos e deveres, o sistema da família e dos estados (profissões, corporações), o da arte e da estética, etc" (LEFEBVRE, 1991:32).

Assim, a cidade aparecerá como a projeção da sociedade sobre um local, ao qual devemos ter direito em sua totalidade ou como o conjunto de necessidades e aspirações para a realização da vida, tendo como base um conjunto de práticas contratuais que se desdobram em normas e posturas que regem a vida urbana.

Estrutura material e simbólica, a cidade se caracterizará como "santuário do valor de trocas", lugar de provisão, de estocagem, de troca no mercado, de concentração de valores. Lugar da produção, da circulação, mas também da reprodução da vida social num sentido amplo. A riqueza cultural se concentrará na cidade, com suas bibliotecas, seus monumentos, estabelecimentos de ensino, imprensa, bem como a memória concreta de diferentes gerações que permite a escrita de sua própria história. Na cidade convivem os "atores" e os escritores num espaço público pleno de possibilidades e ações (ANSAY e SCHOONBRODT, 1989:41).

A cidade foi, e ainda é, o espaço da manifestação e do comprometimento próprios da ação política, associada à exposição diante do outro. "Local de confrontos e das relações (conflitantes) entre desejo e necessidade, entre satisfação e insatisfação", que prima "pela pluralidade, pela coexistência e simultaneidade no urbano de padrões, de maneiras de viver a vida urbana" (LEFEBVRE, 1991:57).

Por um lado, cabe ainda evidenciar o papel histórico da cidade na aceleração dos processos (a troca e o mercado, a acumulação dos conhecimentos e capitais, a concentração desses capitais) e como o local de revoluções" (1991:57). Por outro, "tornando-se centro de decisão ou antes agrupando os centros de decisão, a cidade moderna intensifica, organizando-a, a exploração de toda a sociedade (não apenas 
da classe operária como também de outras classes não dominantes)" (1991:57).

Nos dias atuais, presenciamos uma tensão e uma luta entre os mais diferentes atores pelo uso e a apropriação do espaço da cidade que se esforçam por resistir à tentativa de totalização operada pelo binômio técnica-mercadoria e o seu equivalente: o valor de troca. Boa parte desses atores encontra-se exatamente naqueles lugares onde as relações mercantis ainda esbarram na força do valor de uso impregnada ao espaço. Os espaços populares são notadamente trincheiras dessa resistência.

Em suma, ter direito à cidade significa, portanto, nesse segundo sentido, o direito à participação nos valores - bens públicos, patrimônio e serviços - tanto aqueles que são desigualmente distribuídos pelo mercado, quanto aqueles que são gestados pelo poder público e que são de vital importância para assegurar o bem-estar de seus moradores. Incluem-se aí, os valores simbólicos - culturais, artísticos e estéticos - os valores de uso da cidade e seu preço como bem coletivo.

\section{De habitat a território}

Nas últimas três décadas, a urbanização avançou de maneira tal que promoveu a fragmentação dos conteúdos sociais que permitiam uma maior interação/socialização entre os diferentes espaços da cidade. Praças foram cercadas, acessos a fim de ruas foram fechados. A chamada "arquitetura da violência"6 se transformou na estética dominante e encontra-se em toda parte, com os seus muros altos e gradeamentos. Por todos os cantos, ampliaram-se os controles. Já não é mais possível entrar e sair da favela como antes, sem estar acompanhado ou ter autorização. Nas ruas poucos são aqueles que se arriscam a alguma "pelada" ou brincadeiras. Não só a preocupação com a segurança, mas também o automóvel retirou em muito as crianças da rua. Multiplicaram-se os condomínios fechados de todos os tipos e ordem, dos bairros de classes alta e média a bairros mais populares, bem como os shoppings centers, como novos templos do consumo. Paralelamente a isso, aprofundam-se as desigualdades sociais e a distância entre a riqueza e a pobreza na cidade. Ampliam-se e diversificamse as estratégias de sobrevivência entre as classes sociais e os diferentes atores.

Os rumos tomados pelo desenvolvimento urbano nas grandes aglomerações, sobretudo, têm acentuado o processo de segregação sócio-espacial, com a compartimentação cada vez maior da cidade em territórios estanquizados (HARVEY, 1997:12). De lugares de integração de distintas formas culturais e diversos grupos migratórios, a cidade se fragmentou numa infinidade de minúsculos territórios submetidos à lógica do mercado e à síndrome do medo e da insegurança. As tensões e os conflitos, para não dizer "guerras", multiplicam-se proporcionalmente ao isolamento e à fragmentação.

\footnotetext{
${ }^{6}$ Ver sobre o assunto trabalhos desenvolvidos por Sônia Ferraz no site: http://www.uff.br/arqviol/
} 
A favela, como parte das mutações que ocorreram na cidade, em particular na metrópole Rio de Janeiro, deixou de ser apenas um habitat (ABREU, 1986), distinto no conjunto da cidade, para se transformar em território, espaço de controle e de domínio de grupos armados que operam no mercado ilegal do narcotráfico. Nesse sentido, a favela apartou-se ainda mais dos bairros e de outros espaços da cidade, num reforço ao processo de segregação sócio-espacial, já visível na paisagem. A convivialidade, que em algum momento existiu com maior fluidez social e cultural entre a favela e o bairro, tornou-se extremamente restritiva, permanecendo limitada, muitas vezes ao interior de cada espaço ou comunidade.

Essa convivialidade enfraqueceu-se, também, como um todo no conjunto da cidade e de seu espaço público. A cidade como lugar de encontro, de reunião, de vida comunitária, em geral, perdeu força. Em parte, pelas mudanças decorrentes da própria urbanização e da mercantilização dos espaços, por outro pela precarização das relações de trabalho que agravou, ainda mais, o quadro de sobrevivência da população nas cidades.

Se a urbanidade, num sentido absoluto cresceu, com a aglomeração, a urbanidade relativa tem se reduzido progressivamente. Tem colaborado para isso a transformação de alguns trechos de bairros, o que inclui as favelas, em corredor de passagem para outros bairros, com vias expressas, para acessos a centros comerciais, aeroportos, rodovias, etc. A cidade, em certa medida, tem se tornado um lugar de passagem. Um lugar de "ordem em público", segundo uma dada racionalidade instrumental implementada pelo planejamento estatal, e não de "ordem pública", pactuada entre os diferentes atores. Pela racionalidade instrumental o espaço precisa ser ordenado, de acordo com regras de funcionamento que atendam a interesses econômicos para além das pessoas que por ele transitam ou nele vivem e não que atendam efetivamente a necessidades da população e que garantam, sem restrição, o seu direito à cidade.

Mais do que um processo de territorialização da cidade e estanquização de seus espaços, estamos diante da crise de um projeto ou utopia de compartilhamento da cidade como um todo e por todos. Esta é, portanto, e também, uma crise ética e moral expressa através dos conflitos que envolvem a cidade e o uso do seu espaço. Nosso grande desafio é pensar a cidade como um todo, e a favela dentro desse contexto, de modo a apontar para saídas que remontem e atualizem a utopia do direito à cidade para os seus sujeitos. 


\section{Mudar a Cidade, Mudar a Favela}

A gente quer valer o nosso amor, A gente quer valer nosso suor, A gente quer valer o nosso humor, A gente quer do bom e do melhor (...)

A gente quer é ter muita saúde, A gente quer viver a liberdade, $A$ gente quer viver felicidade (...)

A gente quer viver pleno direito, A gente quer viver todo respeito, A gente quer viver uma nação, A gente quer é ser um cidadão, $A$ gente quer viver uma nação!

(Gonzaguinha)

A cidade como um todo precisa efetivamente se tornar um lugar de bem viver, de pleno direito, de liberdade e de felicidade, como diz o poeta na composição. E isso não é tão simples. Sem mudar a cidade não temos condições de mudar a favela. Sem mudar a favela não temos efetivamente direito à cidade.

A favela deve ser reconhecida, tanto materialmente quanto simbólica e culturalmente como parte da cidade. A cidade por ela passa e nela estende as suas redes. A favela, como parte da cidade, está no mundo das mercadorias, do mercado imobiliário (e da renda que ele pode oferecer), da produção cultural e de serviços. Muitas delas já se urbanizaram ou estão em processo de urbanização e regularização por iniciativa do poder público, com projetos/programas de urbanização, ou por iniciativa dos próprios moradores que, apesar das condições adversas em que vivem, estão sempre procurando melhorar/ampliar suas residências e suas condições de habitabilidade. A favela é um espaço em permanente mutação e desenvolvimento como toda a cidade e a metrópole.

É preciso considerar a favela como parte da dialética do processo de urbanização, que ao mesmo tempo em que desconstrói a cidade - fragmentando o seu conteúdo social, segmentando o tempo da vida das pessoas (trabalho, escola, lazer, etc) em lugares diversos, estanquizando espaços e multiplicando territórios de controle e poderes - também tece o fio de possibilidades concretas que através da iniciativa de diferentes sujeitos e atores (associações, fóruns, movimentos culturais, ONGs, etc), resistem e pressionam o poder público e empresas - chamando a responsabilidade dos mesmos, 
como gestores e produtores do espaço urbano -, recusando-se a continuar a viver a dramática decomposição dos sentidos históricos da cidade, quais sejam: a) o da comunidade e encontro; b) o da proteção e segurança; c) o da lei e ordem; d) o da celebração e mito; e) o da promoção do bem estar comum e felicidade. ${ }^{7}$

É preciso considerar também, no entanto, que não podemos voltar a roda da urbanização para trás. É preciso reconhecer, pensar e trabalhar com a complexidade que assumiu o atual espaço urbano, com "uma vasta tessitura urbanizada, aparentemente caótica, numa sucessão de homogeneidades e de fragmentos dispersos" (SEABRA, 2001:77). Mudar a cidade, portanto, é reconstituir certas relações, valores e sentidos perdidos e inserir outros novos, necessários a uma vida cidadã e que contemple a cidade como um fenômeno complexo. Pensar essa complexidade é considerar a cidade funcionando pela simultaneidade dos eventos da vida cotidiana e pela forte diferenciação interna de seus espaços e suas populações, em intensa cooperação. É pensar num direito à cidade que contemple as diferenças (econômicas, sociais e culturais), inclusive entre as favelas e no seu interior.

Por outro lado, devemos considerar que a cidade sempre foi expressão de relações sociais mais amplas, inseridas a cada tempo, em sistemas sociais e culturais distintos e particularizadas por formações econômico-sociais. Nos dias de hoje, a cidade encontra-se inserida em uma sociedade mundialmente articulada em rede, sob a égide do capitalismo, seus objetivos e suas contradições. Concentração de riqueza, miséria aviltante, tráfico de drogas, violência urbana e violação de direitos, tidos como universais, não são exclusividades de nossas cidades, nem se encontram suspensos no ar, flutuando. A luta para mudar a cidade faz parte de uma luta mais ampla de valorização da vida, de fazer valer os valores humanos e universais, de autodeterminação, de justiça, de eqüidade econômico-social e de respeito às diferenças em confronto com a opressão, a exploração, a reificação, a desumanização e o empresariamento/mercantilização do mundo e das relações promovidas pelo capital.

É preciso apontar no sentido de uma nova ética e cultura para o espaço das cidades. Na prática, na vida cotidiana da cidade, devemos estabelecer como um princípio geral, e por que não dizer um compromisso, a primazia do uso e do valor de uso sobre o valor de troca, tendo a perfeita consciência de que não podemos eliminar este último, mas devemos submetê-lo a uma nova ética. Isso significa (re)imprimir novas práticas na vida social, novos padrões de comportamento e formas novas de uso do tempo e do espaço. "Recoloca-se, assim, a necessidade de rediscutir a alienação" (SEABRA, 2001:82) e esta na vida da cidade e recuperar o sentido desta, cidade, como obra, como criação e finalidade humana para a felicidade.

Em primeiro lugar, isso significa, de cara, por em questão uma determinada racionalidade dominante de conceber, planejar e realizar a gestão da cidade para 0

\footnotetext{
${ }^{7}$ Sobre os sentidos históricos da cidade, ver as obras de MUMFORD, L., 1963 e ANTOLINI, A. \& BONELLO, Y. 1994.
} 
mercado mundial, nos últimos tempos (SÁNCHEZ, 2003). Nessa concepção, a cidade como um todo, é tomada como mercadoria e voltada para atendimento de interesses empresariais globalizados. Nela as funções da cidade e seus espaços devem ser mercantilizados, vistos em termos de sua competitividade e rentabilidade real ou potencial. Em outras palavras, significa dizer que a cidade deve estar a disposição do capital globalizado e seus interesses e a primazia é do valor de troca na cidade. A cidade para quem dela se utiliza no circuito da mercadoria e não para quem nela vive e dela precisa para reproduzir a sua vida cotidianamente.

Assim, para mudar a cidade, é preciso encarar com seriedade esse ponto e trabalhar na contramarcha de seu empresariamento. Por um lado, é preciso concebê-la como um todo em relação, como uma unidade na diversidade, mobilizada, em primeiro lugar, para a reprodução da vida e o bem viver comum, não devendo estar os seus cidadãos subjugados ao valor da mercadoria e à rentabilidade do capital. Por outro, é preciso lutar por uma gestão democrática da cidade, na qual os seus diferentes setores e sujeitos possam estar participando e influenciando em seu planejamento e administração, sugerindo e opinando sobre políticas públicas, bem como na distribuição de seus recursos e receita, através de fóruns, com estas finalidades, e orçamentos participativos. Quem melhor sabe o que precisam as nossas cidades é quem nelas vivem a massacrante jornada de sobrevivência do dia-a-dia.

Em segundo lugar, é preciso ir para além da segregação e disparidades sócioespaciais existentes, formulando uma política urbana que contenha medidas que possam impedir que a estanquização (sócio-político-cultural) dos espaços da cidade e a constituição de territórios de controle e de poder se instalem de modo mais definitivo na cidade. Nesse sentido, é necessário trabalhar na contramão de estereótipos e preconceitos que estigmatizam grupos e classes sociais relacionando-os a determinados espaços da cidade (como as favelas e as periferias, por exemplo) e que trazem forte conteúdo racista e ideológico, que erguem muros invisiveis na cidade e fomentam o medo e a insegurança. É fato que a violência urbana existe, sob vários aspectos, e esta deva ser enfrentada igualmente no âmbito das políticas públicas com a devida atenção. Entretanto, não podemos permitir que a difusão do medo e da insegurança, apoiados em argumentos ideológicos ou racistas, gere interdições à convivência (troca interpessoal e coletiva) e restrições ao uso de determinados espaços da cidade. A fuga para condomínios exclusivos e fechados, em diferentes bairros da cidade, por parte das classes mais abastadas, encontra-se, em certa medida, dentro dessa perspectiva.

É necessário, portanto, trabalharmos para mudar determinadas representações sociais que dificultam a própria idéia de cidade como unidade e encontro de diferentes, e negam, na prática, um dos sentidos do direito à cidade, condição para que os demais direitos se realizem, que é o direito de se ter direito à cidade como um todo, a seus espaços, a seus serviços, vias, patrimônios e bens públicos, em geral. Igualmente, precisamos mudar a representação social de favela, como espaço da ausência, da 
carência, da ilegalidade, da desordem, do subnormal, enfim, da não-cidade, visto de modo homogêneo, excludente e divorciado da mesma. A favela, também como os demais espaços da cidade, é lugar de vida, de criação, de arte, de alegrias e dores, de estratégias de sobrevivência, que ao contrário de equívocos, têm se apresentado como soluções para essa população que habita espaços populares sob condições, ambientais, econômicas e sociais extremamente adversas. Mais do que isso, os espaços populares da cidade têm conferido a ela parte de sua própria identidade. É notório o papel que o samba e as escolas de samba tiveram nesse aspecto na história da cidade do Rio de Janeiro (FERNANDES, 2001), a ponto de dar-lhe uma projeção internacionalmente reconhecida.

Em terceiro lugar, é necessário uma política urbana que verdadeiramente, (re)valorize o espaço público - ruas, praças, vias, parques, jardins, passeios, etc - como espaços eminentemente de uso coletivo, acima dos interesses individuais ou de grupos. Nesse sentido, é fazer valer a lei do Estatuto da Cidade ${ }^{8}$, em vigor desde junho de 2001, que põe em destaque a função social da propriedade urbana e da cidade. No seu Art. $2^{\circ}$, o Estatuto da Cidade, destaca que "A política urbana tem por objetivo ordenar o pleno desenvolvimento das funções sociais da cidade e da propriedade urbana" e estabelece como a primeira de suas diretrizes gerais: "I- garantia do direito a cidades sustentáveis, entendido como direito à terra urbana, à moradia, ao saneamento ambiental, à infra-estrutura urbana, ao transporte e aos serviços públicos, ao trabalho e ao lazer, para as presentes e futuras gerações".

Essa diretriz vem, assim, ao encontro do segundo sentido do direito à cidade, já assinalado por nós, que é o da reivindicação, pelo indivíduo, de recursos institucionais necessários ao seu bem-estar. Pensamos que para que essa diretriz traduza, na sua aplicação, efetivamente, o direito à cidade, se faz necessário que ela assegure também as favelas a sua aplicação. Enquanto isso não acontecer, o direito à cidade aludido pela lei será incompleto, seletivo e restrito a determinadas frações da cidade. Ou seja, não basta constar em lei, é preciso ser amplamente efetivado através de nossas políticas urbanas.

Em quarto lugar, cabe a favela e seus moradores, criar mecanismos de participação e organização que exijam a sua inclusão nas políticas urbanas, e públicas em geral, e que a reconheçam como parte da cidade, como qualquer outro bairro, com história, sociabilidade urbana e com singularidades próprias de sua comunidade. Não dá mais para ver as favelas sendo tratadas/consideradas como aglomerados populacionais homogêneos e antiurbanos. Nesse sentido, as próprias comunidades desses espaços populares precisam (re)construir suas identidades, produzir a sua própria história e informações, manifestar o seu próprio olhar sobre a cidade e se integrar a todas as esferas da vida e do trabalho pertencentes a cidade, até mesmo aquelas que exigem

\footnotetext{
${ }^{8}$ Cf. Lei $\mathrm{N}^{\circ} 10.257$, de 10 de julho de 2001. Regulamente os Artigos 182 e 183 da Constituição Federal, estabelece diretrizes gerais da política urbana e dá outras providências.
} 
maior qualificação intelectual. É preciso que essas comunidades se promovam ou se "auto-ocupem" socialmente, através de ações coletivas e criativas, num movimento capaz de construir um contra-espaço que neutralize ou vá de encontro aos territórios de controle e poder, sob o domínio do tráfico de drogas.

É necessário, enfim, que os espaços populares integrem-se com a cidade para além da divisão social do trabalho e do mercado (legal e ilegal), para além dos momentos lúdicos e de festa da cidade, como o carnaval e o reveillon. É necessário que as favelas se integrem material e simbolicamente ao espaço da cidade, fazendo parte de sua representação, num modelo cívico-territorial que garanta plenamente a quem nelas vivem os seus direitos elementares de cidadão. O paradoxo de mudar a favela é o de mudar a cidade para se ter verdadeiramente direito a ela e à sua utopia de felicidade.

\section{THE RIGHT TO THE CITY'S UTOPY: POSSIBILITIES TO SURPASS FAVELA-DISTRICT DICHOTOMY IN RIO DE JANEIRO}

Abstract: The right to the city's utopy specifically in Rio de Janeiro, begins by surpassing the dichotomy approach between favela and the city. For this purpose, it is necessary, for the favela dwellers, the feeling of citizens as well as those with home outside the favelas. The right to the city's utopy must bring to the favela the utopy to the city in itself- a non-fragmented city in terms of oppositions like "asphalt"-favela, north-south, beach-suburb and where everybody has right to their center(s). These oppositions express much more the differences of location and present themselves full of segregation, stereotypes and ideologies. On the other hand, the right to the city, as historical possibility, can not be thought just from the favela. People that live there have a contribution for a practical construction of this right.

Keywords: Favela, Right to the City, Urban Segregation.

\section{A UTOPIA DO DIREITO À CIDADE: POSSIBILIDADES DE SUPERAÇÃO DA DICOTOMIA FAVELA-BAIRRO NO RIO DE JANEIRO}

Resumo: A utopia do direito à cidade, no caso específico do Rio de Janeiro, começa, obrigatoriamente, pela superação da visão dicotômica favela-cidade. Para isso, é preciso que os moradores da favela possam sentir-se tão cidadãos quanto os que têm moradias fora das favelas. A utopia do direito à cidade tem de levar à favela a própria utopia da cidade. Uma cidade que não se fragmente em oposições asfaltofavela, norte-sul, praia-subúrbio e onde todos tenham direito ao(s) seu(s) centro(s). Oposições que expressam muito mais do que diferenças de localização e que se apresentam recheadas de segregação, estereótipos e ideologias. Por outro lado, $o$ direito à cidade, como possibilidade histórica, não pode ser pensado exclusivamente a partir da favela. Mas as populações que aí habitam guardam uma contribuição inestimável para a construção prática desse direito. Isso porque, das experiências vividas, emergem aprendizados e frutificam esperanças e soluções. Para que a favela seja pólo de um desejo que impulsione a busca do direito à cidade, é necessário que ela se pense como parte da história da própria cidade e sua transformação em metrópole.

Palavras-chaves: Favela, Direito a cidade, Segregação urbana. 


\section{BIBLIOGRAFIA}

ABREU, Mauricio de A. 1987. A periferia de ontem: o processo de construção do espaço suburbano do Rio de janeiro. Espaço e Debates, n. 21.

ANSAY, Pierre e SCHOONBRODT, René. 1989. Penser la ville: choix de textes philosophiques. Bruxelles: AAM.

ANTOLINI, André e BONELLO, Yves-Henri. 1994. Les villes du désir. Paris: Éditions Galilée.

ARISTÓTELES. 1991. A politica. São Paulo: Martins Fontes. Tradução: Roberto Leal Ferreira, feita a partir da versão francesa de Marcel Prelot.

BRASIL. Congresso Nacional. Lei 10.257, de 10 de julho 2001. Estatuto da Cidade.

FERNANDES, Nelson da Nobrega. 2001. Escolas de samba: sujeitos celebrantes e objetos celebrados. Rio de Janeiro: Arquivo Geral da Cidade.

HARVEY, David. 1997. Las ciudades fragmentadas. Pagina 12, Buenos Aires, 23-3-97.

LEFEBVRE, Henri. 1991. O direito à cidade. São Paulo: Ed. Moraes.

MUMFORD, Lewis. 1965. A cidade na história. Belo Horizonte, Itatiaia. (1º Vol.)

OLIVEIRA, Márcio Piñon. 1999. Um conceito de cidadania para se trabalhar a cidade. Revista GEOgraphia, Ano1, n.1, junho.

SÁNCHEZ, Fernanda. 2003. A reinvenção das cidades para um mercado mundial. Chapecó: ARGOS.

SEABRA, Odette Carvalho de Lima. 2001. Urbanização e fragmentação: apontamentos para o estudo do bairro e da memória urbana. In: SPOSITO, M. E. B. (Org.) Urbanização e cidades: perspectivas geográficas. Presidente Prudente: UNESP / GAsPERR. 